Carlos Machado de Freitas 1

Carlos Augusto Vaz de Souza 1

Jorge Mesquita Huet Machado 1

Marcelo Firpo de Souza Porto 1

\title{
Acidentes de trabalho em plataformas de petróleo da Bacia de Campos, Rio de Janeiro, Brasil
}

\author{
Work-related accidents on offshore \\ oil drilling platforms in the Campos Basin, \\ Rio de Janeiro, Brazil
}

1 Centro de Estudos em Saúde do Trabalhador e Ecologia Humana, Escola Nacional de Saúde Pública, Fundação Oswaldo Cruz. Rua Leopoldo Bulhões 1480, Rio de Janeiro, $R J$ 21041-210, Brasil.

\begin{abstract}
The offshore oil industry is characterized by complex systems in relation to technology and organization of work. Working conditions are hazardous, resulting in accidents and even occasional full-scale catastrophes. This article is the result of a study on work-related accidents in the offshore platforms in the Campos Basin, Rio de Janeiro State. The primary objective was to provide technical back-up for both workers' representative organizations and public authorities. As a methodology, we attempt to go beyond the immediate causes of accidents and emphasize underlying causes related to organizational and managerial aspects. The sources were used in such a way as to permit classification in relation to the type of incident, technological system, operation, and immediate and underlying causes. The results show the aggravation of safety conditions and the immediate need for public authorities and the offshore oil industry in Brazil to change the methods used to investigate accidents in order to identify the main causes in the organizational and managerial structure of companies.
\end{abstract}

Key words Occupational Accidents; Occupational Health; Petroleum; Accident Prevention

Resumo Nas plataformas de petróleo, sistemas complexos em termos de tecnologia e organização do trabalho, as condições de trabalho são perigosas, resultando em acidentes de trabalho e, por vezes, em verdadeiras catástrofes. Este artigo resulta da investigação de acidentes de trabalho nas plataformas de petróleo da Bacia de Campos, no Estado do Rio de Janeiro. Teve como objetivo inicial fornecer subsídios para que representantes dos trabalhadores e instituições públicas pudessem ter elementos técnicos para aprofundar no futuro as investigações e desenvolverem estratégias de controle e prevenção de acidentes. A metodologia de investigação procurou ampliar a análise para além das causas imediatas dos acidentes, visando caracterizar falhas subjacentes de natureza organizacional e gerencial, ou mesmo condicionantes macroestruturais. Os resultados apontam tanto para o agravamento das condições de segurança, como para a necessidade imediata de os órgãos públicos envolvidos na vigilância em saúde do trabalhador e das empresas de exploração do petróleo mudarem suas técnicas de investigação de acidentes de modo a permitir estratégias de controle e prevenção mais amplas no seu escopo e impacto.

Palavras-chave Acidentes do Trabalho; Saúde Ocupacional; Petróleo; Prevenção de Acidentes 


\section{Introdução}

Este artigo resulta da investigação de acidentes de trabalho nas plataformas de petróleo da Bacia de Campos, no Estado do Rio de Janeiro, no período de 18 de agosto de 1995 a 14 de abril de 1997. O objetivo desta investigação foi fornecer subsídios para que representantes dos trabalhadores, por meio do Sindicato dos Petroleiros do Norte Fluminense (SINDIPETRO-NF) e instituições públicas do poder executivo (Câmara Técnica da Indústria Química, Petroquímica e Petroleira do Conselho Estadual de Saúde do Trabalhador do Rio de Janeiro - CT-QPP/ CONSEST) e legislativo (Comissão Parlamentar de Inquérito para apurar denúncias de falta de segurança e condições de trabalho nas plataformas petrolíferas no Estado do Rio de Janeiro da Assembléia Legislativa do Estado do Rio de Janeiro - ALERJ) pudessem ter elementos técnicos para aprofundar no futuro as investigações e desenvolverem estratégias de controle e prevenção de acidentes que possibilitassem melhorar as condições de trabalho e reduzir a freqüência e a gravidade dos acidentes. Ainda que os autores não tenham participado conjuntamente da investigação iniciada pelo poder judiciário, particularmente o Ministério Público do Trabalho (MPT), foi entregue uma cópia do relatório técnico da investigação de modo a subsidiar sua atuação, embora esta tenha sido limitada e isolada das outras.

Este tipo de investigação se faz urgente e necessário quando consideramos que na história da exploração do petróleo na Bacia de Campos há o registro de catástrofes como os acidentes ocorridos na Plataforma de Enchova em 1984 e 1988. O primeiro resultou em 37 óbitos imediatos; o segundo, na destruição total do convés e da torre, totalizando um prejuízo de 500 milhões de dólares (SINDIPETRO-NF, 1997). A memória de acidentes como o da Plataforma de Enchova em 1984, bem como o da Plataforma de Piper Alpha (no Mar do Norte, em 1988), o qual resultou no óbito de 165 dos 228 trabalhadores presentes no dia do acidente $(72 \%$ do contingente) simbolizam o grande potencial de perigo que existe nas plataformas de petróleo e exigem que instituições públicas de pesquisa, junto com instituições dos poderes executivo, legislativo e judiciário relacionadas à saúde do trabalhador, permanentemente, levem em consideração o que vem ocorrendo tanto na Bacia de Campos como em outros estados onde há exploração marítima de petróleo, não cabendo omissões quando o que se encontra em jogo é a saúde e a vida de milhares de trabalhadores, tanto como o bem estar de suas famílias.
Embora seja comum considerar que o trabalho industrial foi e está sendo bastante estudado, levantamento realizado por nós nas revistas Cadernos de Saúde Pública, Revista de Saúde Pública e Revista Brasileira de Saúde Ocupacional, no período de 1980 ao primeiro semestre de 1999, constatou que de 148 artigos referentes ao tema "acidentes", 71 (48\%) tratavam de acidentes de trabalho e destes 17 $(11,5 \%)$ eram específicos sobre acidentes em indústrias. Apenas dois, correspondentes a 2,8\% do total de 71 artigos referentes aos acidentes de trabalho, tratavam de acidentes de trabalho em indústrias químicas, petroquímicas e petroleiras. No período abrangido por este levantamento (1980 ao 1o semestre de 1999), não foi encontrado nenhum artigo que tratasse do tema "acidentes de trabalho em plataformas de petróleo", mesmo que tenha sido exatamente nas décadas de 80 e 90 que a exploração marítima do petróleo tenha dado seu maior salto no país, particularmente na Bacia de Campos, atualmente responsável por cerca de $75 \%$ da produção nacional, colocando o Brasil no 17으 lugar do ranking dos maiores produtores do mundo (Camacho \& Almeida, 1997) e com o registro do sétimo acidente mais grave do mundo em relação ao número de óbitos em um único evento (OIT, 1993). Assim, os objetivos deste artigo são contribuir para: 1) revelar a gravidade do quadro de acidentes de trabalho resultantes da exploração marítima de petróleo no Brasil; 2) mudar a lógica predominante das investigações de acidentes de trabalho no país, na qual os trabalhadores são simultaneamente vítimas e, na grande maioria dos casos, culpados até que alguém prove o contrário. Acreditamos que análises de acidentes de trabalho que permitam articular e contextualizar os eventos em relação aos seus condicionantes sociais, tecnológicos e organizacionais presentes na gestão do processo de trabalho permitam ações de vigilância em saúde do trabalhador (AVST) que efetivamente contribuam para mudar o atual quadro de acidentes não só nas plataformas de petróleo, mas também o geral do país. Nesse sentido, este artigo faz parte de um esforço maior dos autores no desenvolvimento metodológico de uma análise interdisciplinar e participativa de acidentes (AIPA) no campo da saúde dos trabalhadores (Machado et al., 2000). 


\section{Condições de trabalho e acidentes em plataformas de petróleo}

Plataformas de petróleo são instalações bastante complexas e algumas, principalmente as grandes plataformas, podem incluir a produção e armazenagem de óleo e gás à alta pressão, a perfuração de poços e obras de construção e manutenção (Booth \& Butler, 1992). Por operarem distantes da costa e de socorros imediatos, necessitam de certo grau de autonomia, exigindo-se um conjunto de serviços tais como alimentação e alojamento das tripulações (por vezes para mais de 200 pessoas embarcadas ao mesmo tempo), fornecimento de energia elétrica, compressores e bombas, água, transportes para a costa (barcos ou helicópteros), meios para cargas e descargas, telecomunicações, serviços médicos e botes salva-vidas, além de outros meios de salvamento, o que requer um elevado nível de coordenação (OIT, 1993). O período de dias de trabalho embarcado no mar e dias de descanso em terra varia. Em alguns países possui uma alternância de 14/14 (Reino Unido), $7 / 7$ (Estados Unidos), ou mesmo uma progressão de 14/14 no primeiro ciclo, 14/21 no segundo ciclo e 14/28 no terceiro ciclo (Noruega). Em termos de horas de trabalho durante o período de embarque, o mais comum são 12 de trabalho para 12 de descanso, porém, o período de horas efetivamente trabalhadas, incluindo as extras, freqüentemente chega a ser de 14 horas. Há alguns postos de trabalho em que a jornada pode chegar a 17 horas. De qualquer modo, independentemente da modalidade de turnos estabelecida, alguns trabalhadores permanecem de prontidão durante todo o tempo em que se encontram na plataforma.

Por suas características intrínsecas, o trabalho nas plataformas inclui uma ampla diversidade de atividades tais como partidas de instalações e produção; paradas e redução da produção; manuseio de equipamentos e materiais perigosos; controle manual do processo; monitoramento da produção por sistema supervisório; manutenções preventivas e corretivas; limpezas de máquinas e equipamentos; transporte de materiais; operações manuais e mecânicas de levantamento de cargas; inspeções e testes de equipamentos; transporte marítimo e aéreo; cozinha; limpeza; construção e reforma, entre outras (Rundmo, 1992). Isto faz com que nas plataformas de petróleo se conjuguem de forma única os riscos típicos de muitas atividades de produção e manutenção industriais de refinaria, tratamento e unidades de produção de energia com outros próprios das tarefas relacionadas com a exploração de gás e petróleo, como a perfuração e os poços de produção, associados aos de transporte aéreo (helicópteros) e marítimos, de construção civil nas atividades de reparo, construção e reforma, de mergulhos rasos e, principalmente, profundos, entre outros (OIT, 1993). Este conjunto de atividades se conjuga com um sistema tecnológico em que as partes e unidades se encontram bastante próximas, exigindo-se bastante cuidado e atenção nos sistemas de isolamento. Válvulas corretas devem ser fechadas, flanges devem ser colocados e cada isolamento cuidadosamente controlado em altos padrões. Se isto não ocorre, há o risco de que hidrocarbonetos à alta pressão possam vazar e encontrar uma primeira chama ou faísca provenientes do próprio trabalho, gerando acidentes com conseqüências muito sérias (Booth \& Butler, 1992). Estas características fazem com que todas as atividades de trabalho, em todas as etapas, contenham riscos intrínsecos e variados, resultantes de uma estreita correlação e de uma potencialização recíproca entre os fatores técnicos, as condições humanas e as variações do ambiente natural (Sevá Filho, 2000).

O trabalho em unidades de processo como as plataformas de petróleo pode ser compreendido por quatro aspectos que se interrelacionam e o caracterizam. Ele é simultaneamente contínuo, complexo, coletivo e perigoso (Ferreira \& Iguti, 1996). Contínuo, já que a produção flui durante as 24 horas do dia ao longo do ano, exigindo o revezamento de vários grupos de trabalhadores para acompanhamento da mesma. Complexo porque as diversas partes do sistema tecnológico se encontram interligadas numa estrutura de rede que impede que se possua um controle total do sistema, sempre sujeito a um certo grau de imprevisibilidade e de desencadeamento de efeitos do tipo dominó em caso de incidentes e acidentes. Coletivo porque o funcionamento da unidade só é possível pelo trabalho de equipes em que as atividades são altamente interdependentes. Perigoso porque está relacionado ao processamento de hidrocarbonetos que evaporam, incendeiamse ou explodem, ao uso de compostos químicos tóxicos para os homens e para o ambiente e à operação de máquinas e equipamentos que podem desencadear acidentes poderosos, com o potencial de causar múltiplos óbitos e lesões (Sevá Filho, 2000).

Assim sendo, para que se compreenda a natureza dos problemas de segurança no trabalho em plataformas de petróleo é importante que se tenha em conta os seguintes aspectos que o caracterizam, os quais, segundo o relatório "Segurança do Trabalho em Instalações Pe- 
trolíferas no Mar e Assuntos Conexos", da Organização Internacional do Trabalho (OIT, 1993) são: a) uma ampla série de atividades perigosas que se realiza em um espaço de trabalho bastante reduzido; b) os trabalhadores das plataformas não só têm de trabalhar, mas também viver em contato permanente com os riscos; c) as situações de perigo de incidentes e acidentes se agravam pela presença de hidrocarbonetos, de modo que se colocam dificuldades no tempo requerido para evacuar o pessoal em condições de segurança, acrescentando-se ainda os relacionados possivelmente ao mau tempo no mar; d) há uma grande variedade de empresas e de gestão do trabalho que atuam no ambiente confinado das plataformas associado a um grande número de trabalhadores em regime de subcontratação, muitos dos quais devem mudar continuamente de local e de atividade de trabalho; e) as dificuldades de regulamentação de numerosas instalações móveis e que requerem critérios particulares, especialmente para reduzir ao mínimo as duplicações e evitar conflitos entre as legislações municipal, estadual e federal, além de convênios marítimos internacionais. A diversidade de atores e instituições reguladoras e fiscalizadoras como por exemplo a Marinha e diversos órgãos públicos nas áreas da saúde, do trabalho e do meio ambiente, além dos poderosos interesses políticos e econômicos envolvidos tornam mais complexas as atividades de regulamentação e fiscalização na área.

Se o trabalho nas plataformas já é em si perigoso, é importante considerar que os riscos são agravados por outros fatores identificados pelo estudo realizado por Sutherland \& Cooper (1991) com trabalhadores em alto mar na Europa (310 homens empregados em 18 empresas contratadas e 14 companhias petroleiras em 97 instalações), sendo os mesmos fontes de estresse e conectados com os anteriormente apontados, podendo estar contribuindo para os acidentes, dos quais gostaríamos de destacar: a) o caráter rotineiro do trabalho; b) o desconhecimento do que se constitui o trabalho no mar por parte do pessoal de gerência que se encontra em terra, agravando a insatisfação dos trabalhadores das plataformas com a gestão administrativa por parte dos mesmos; c) o transporte quando as condições meteorológicas são desfavoráveis; d) a falta de segurança no emprego; e) as desagradáveis condições de trabalho devido ao ruído.

Particularmente, no que se refere aos trabalhadores terceirizados, Sutherland \& Cooper (1991) identificaram que o descontentamento era maior entre os mesmos, os quais sofriam maior estresse devido às características imprevisíveis do trabalho e pelo fato de não gozarem da mesma situação do pessoal das empresas exploradoras no que tange aos rendimentos e perspectivas de carreira. Estes dados são preocupantes quando consideramos que os trabalhadores terceirizados, embora realizando atividades que variam em função do tipo de instalação, em geral chegam a representar dois terços a três quartos do total da mão de obra ocupada nas plataformas (OIT, 1993).

No que se refere especificamente aos acidentes de trabalho nas plataformas, Sutherland \& Cooper (1991) constataram na amostra estudada que $29 \%$ dos trabalhadores referiu ter sofrido danos corporais em acidentes ocorridos nas plataformas. Percentual próximo foi encontrado no estudo realizado por Rundmo (1994) em cinco empresas e oito plataformas da Norwegian Continental Shelf, na Noruega, o qual envolveu 915 trabalhadores (92\% do total de trabalhadores). No estudo de Rundmo (1994), $25 \%(n=229)$ dos trabalhadores responderam que foram lesionados alguma vez durante o seu trabalho nas plataformas e, dentre estes, $40 \%(\mathrm{n}=92)$ vivenciaram mais de um acidente, totalizando 355 lesões. Do total de 355 lesões, apenas $34 \%$ não resultaram em ausência do trabalho até o próximo turno. Do restante, $54 \%$ geraram a necessidade de repatriação, visto haver grande número de trabalhadores estrangeiros, e $12 \%$ implicaram o afastamento do trabalho para tratamento fora da plataforma.

De acordo com o estudo de Rundmo (1994), as atividades de trabalho predominantes incluídas no universo de 355 lesões foram manutenção preventiva (10\%), trabalhos de reparo (15\%) e operações manuais de levantamento de cargas (16\%). Os resultados de Rundmo (1994) apontam que os trabalhadores envolvidos nas atividades de levantamento de cargas, particularmente as manuais, e de manutenção e reparo, os quais são em sua quase totalidade terceirizados, foram os que sofreram o maior número de acidentes.

Em relação à freqüência, segundo a OIT (1993), a maioria das análises estatísticas revela uma incidência muito maior entre os trabalhadores terceirizados. Dentre as causas para isto podemos citar o fato de estes trabalhadores realizarem a maioria das atividades mais perigosas ao mesmo tempo em que possuem tanto menor capacitação e treinamento, como desfrutam menos direitos quando comparados com os trabalhadores diretos das empresas, tendo isto diversas implicações em termos de segurança (OIT, 1993). Um estudo realizado na Noruega pelo sindicato dos trabalhadores, por 
exemplo, revelou que os trabalhadores terceirizados realizavam tarefas de manutenção de poços de um modo em que eram violadas de forma regular e sistemática as leis e regulamentações sobre horas de trabalho, descansos, tempo de permissão para ficar em terra, registro e pagamento de horas extras, além de outros (OIT, 1993).

Em relação à gravidade, registrou-se um total de 960 óbitos em 47 acidentes ocorridos em plataformas de petróleo no mundo entre 19701991, com uma média de 20,4 óbitos por acidente (OIT, 1993). É importante observar que os riscos de acidentes variam conforme o tipo de instalação e de atividade. Pode se observar na Tabela 1, que em relação as atividades de trabalho que apresentaram maior número de óbitos, predominaram as de perfuração, correspondendo a $61,8 \%$ do total, vindo em seguida a de produção, com $37,4 \%$ e de reparo e construção, com $0,8 \%$. Na Tabela 1 chama a atenção o fato de $79,1 \%(n=349)$ dos óbitos nas atividades de perfuração e 70,0\% $(n=187)$ dos óbitos nas atividades de produção terem ocorrido em acidentes em que houve perda total (Nível 1) ou danos materiais graves (Nível 2) nas plataformas, com predomínio de eventos como incêndios, explosões e colapsos estruturais.

\section{Metodologia e fontes}

Nos últimos anos tem se revelado cada vez mais a ineficiência das abordagens de investigações de acidentes de trabalho que, ao atribuírem continuamente a responsabilidade aos trabalhadores pelos eventos em que são vítimas, acabam tendo muito mais o papel de manter determinadas estratégias de controle das relações sociais de trabalho pelas empresas do que um efetivo gerenciamento dos riscos no processo de produção. Objetivando o desenvolvimento de estratégias de controle e prevenção mais eficazes, novas abordagens metodológicas de investigação vêm sendo criadas, especialmente no que se refere aos sistemas tecnológicos complexos presentes em setores como tecnologia aeroespacial, usinas nucleares, indústrias químicas de processo contínuo e plataformas de petróleo. Tais abordagens enfatizam os contextos social e organizacional em que padrões de produção inseguros são fixados e acidentes ocorrem. Dentre estas abordagens destacamos as desenvolvidas nos âmbitos da engenharia (Kletz, 1993; Paté-Cornell, 1993; Lorry, 1999), da ergonomia (Leplat \& Terssac, 1990; Meshkati, 1991; Wisner, 1994), da sociologia (Perrow, 1984; Wynne, 1988; Dwyer, 1991) e da epidemiologia (Andersson, 1991; Menckel \& Kullinger, 1996), possibilitando o desenvolvimento de sistemas de informações que permitam revelar e apreender os aspectos gerenciais e organizacionais (Drogaris, 1992; Rasmussen, 1995). No Brasil, estas abordagens vêm sendo incorporadas a AVSTs e trabalhos acadêmicos (Porto, 1994; Freitas, 1996; Machado, 1996); todavia, ainda pouco divulgadas em revistas científicas nacionais.

Estas abordagens de investigação são poderosos instrumentos para revelar as subjacentes fragilidades da matriz sócio-organizacional das empresas em que ocorrem os acidentes e conduzem a uma ampla análise. Em termos metodológicos, esta estratégia permite uma maior aproximação com o trabalho real que é realizado no dia a dia do chão-da-fábrica dos processos produtivos, o que inclui a participação dos trabalhadores (Backström \& Döös, 1995) e a ampliação da análise para além das causas imediatas dos acidentes, visando caracterizar fa-

Tabela 1

Número de óbitos por atividades de trabalho (perfuração, produção, reparo e construção) e nível de danos materiais no mundo entre 1970-1989.

\begin{tabular}{|c|c|c|c|c|c|c|c|}
\hline \multirow[t]{2}{*}{ Tipos de atividades } & \multicolumn{6}{|c|}{ Danos* } & \multirow{2}{*}{$\begin{array}{c}\text { Total } \\
n\end{array}$} \\
\hline & $\begin{array}{c}\text { Nível } \\
n\end{array}$ & $\begin{array}{c}\text { Nível } 2 \\
\mathrm{n}\end{array}$ & $\begin{array}{c}\text { Nível } \\
\mathrm{n}\end{array}$ & $\begin{array}{c}\text { Nível } \\
\mathrm{n}\end{array}$ & $\begin{array}{c}\text { Nível } \\
\mathrm{n}\end{array}$ & $\begin{array}{c}\text { Nível } 6 \\
n\end{array}$ & \\
\hline Perfuração & 210 & 139 & 13 & 48 & 31 & 0 & 441 \\
\hline Produção & 166 & 21 & 33 & 23 & 24 & 0 & 267 \\
\hline Reparo/Construção & 0 & 0 & 4 & 2 & 0 & 0 & 6 \\
\hline Total & 376 & 160 & 50 & 73 & 55 & 0 & 714 \\
\hline
\end{tabular}

* Nível de gravidade quanto aos danos materiais: 1 = Perda Total; 2 = Grave;

3 = Considerável; 4 = Leve; $5=$ Nenhum; $6=$ Desconhecido.

Fonte: OIT, 1993 
lhas subjacentes de natureza organizacional e gerencial, ou mesmo condicionantes macroestruturais (Paté-Cornell, 1993; Woolfson et al., 1996; Machado et al., 2000).

Como resultado deste tipo de abordagem, em que se estabelecem pontos de contato entre análises de casos singulares e abordagens coletivas, buscam-se a formulação e a implementação de estratégias de gerenciamento dos riscos de acidentes industriais mais amplas em seu escopo e impacto, o que pode incluir a formulação e a implementação de novas políticas públicas, culturas organizacionais e modelos de gerenciamento.

A implementação prática desta metodologia deve ser flexível e contextualizada. Para tanto podem ser adotadas abordagens mais diretas e que permitam a geração de fontes primárias, como observações nos locais de trabalho, entrevistas individuais com os trabalhadores e gerentes, grupos focais e análises coletivas do trabalho, assim como indiretas, valendo-se de fontes secundárias, tais como fontes documentais da empresa, do sindicato e de instituições públicas do executivo, legislativo e judiciário, caso haja. Idealmente, devem ser conjugadas abordagens diretas e indiretas, envolvendo a participação dos trabalhadores.

Contudo, dado o caráter freqüentemente conflitivo dos acidentes de trabalho, e em particular o contexto em que este trabalho de investigação foi realizado e o forte poder político e econômico da empresa responsável até então pela exploração do petróleo na Bacia de Campos no período, pesquisadores, técnicos do Programa de Saúde do Trabalhador do estado, assessores técnicos e representantes do SINDIPETRO-NF foram impedidos de ter acesso às plataformas e, por conseguinte, de realizarem entrevistas e observações in loco. Dificuldades internas do próprio sindicato também dificultaram a possibilidade de se organizar em grupos focais para discussão ou análise coletiva do trabalho.

Frente a isto trabalhou-se com uma ampla variedade de fontes secundárias. Tal abordagem, ainda que limitada, propiciou a sistematização e aprofundamento de diversos aspectos gerenciais e organizacionais relacionados aos acidentes ocorridos e não indicados por outros relatórios técnicos produzidos. Foram utilizados os documentos fornecidos pelo SINDIPETRO-NF à CT-QPP/CONSEST, ao MPT, constantes do Procedimento Prévio 017/96, e a CPI da ALERJ, sendo estes: relatórios de ocorrências anormais (ROAs); relatórios de acidentes com lesões (RALs); laudos técnicos da empresa; laudos técnicos da Capitania dos Portos; atas de reunião da CIPA; comunicados internos; estatísticas de acidentes da empresa; dossiê do SINDIPETRO-NF para a Comissão Parlamentar de Inquérito da Assembléia Legislativa do Rio de Janeiro; relatórios de inspeção da empresa; comunicações de acidentes de trabalho (CATs).

Em uma primeira etapa, este conjunto de fontes foi dividido por tipo de evento e permitiu identificar o conjunto de eventos que constituiria o universo de análise: 64 eventos (51 acidentes, 10 incidentes e 3 eventos não definidos). Esse universo esteve delimitado pela opção de não trabalharmos com os eventos envolvendo navios-sonda, transporte aéreo por helicópteros, embarcações de transporte de pessoal e materiais, e os ocorridos na atividade de mergulho profissional. Definimos acidentes como sendo os eventos que tiveram como conseqüências óbitos, lesões, efeitos adversos à saúde ou danos ao meio ambiente e aos equipamentos. Foram considerados incidentes os casos que não resultaram conseqüências diretas sobre a saúde, o meio ambiente e os equipamentos.

Na segunda etapa, montou-se um pequeno banco de dados com o conjunto dos 64 eventos. Para a montagem deste banco de dados, tomaram-se como referência as variáveis básicas adotadas pela União Européia para o Major Accident Reporting System (MARS), sistema de informação de acidentes em indústrias de processo químico (Drogaris, 1992; Rasmussen, 1995), e que podem, resguardadas as diferenças que lhes são específicas, servir de referência inicial para plataformas de petróleo. As variáveis gerais para o banco de dados foram: 1) data da ocorrência; 2) número do evento; 3) tipo de acidente; 4) tipo de atividade; 5) plataforma em que ocorreu o evento; 6) sistema tecnológico envolvido; 7) modo de operação; 8) produtos envolvidos; 9) conseqüências (lesões, evacuações, danos ambientais, danos materiais, perda da produção e prejuízos financeiros); 10) breve descrição do evento; 11) causas imediatas; 12) causas subjacentes; 13) fontes. Para as variáveis gerais de $3,4,6,7,9,11$ e 12 foram definidas variáveis específicas tendo-se como referência as variáveis adotadas no MARS.

A tipificação dos acidentes (variável 3) foi ampliada em relação ao MARS, já que o nosso universo de acidentes englobou tanto os eventos considerados por este sistema (explosões, incêndios e emissões) quanto eventos como choques elétricos e quedas e rompimento de material, chamados por Rundmo (1992) de acidentes triviais. Os incidentes não foram tipificados. Adaptações foram feitas na variável geral 6, uma vez que o sistema tecnológico das plataformas possui especificidades não encon- 
tradas nas indústrias de processo químico. Em relação à variável 12, destacamos a inclusão do item "subcontratados" na categoria omissões gerenciais/organizacionais, considerado especialmente importante pelo envolvimento de trabalhadores de empresas terceirizadas em um número elevado de eventos. Para este artigo produzimos tabelas para as variáveis $3,6,7$, 11 e 12. Um dos tipos de conseqüências (variável 9) consideradas por nós, as lesões em trabalhadores, foram inseridas na tabela dedicada à variável 3, em que uma das colunas representa o número de trabalhadores lesionados para cada tipo de acidente.

\section{Os acidentes de trabalho nas plataformas de petróleo da Bacia de Campos}

\section{Condições de trabalho nas plataformas de petróleo da Bacia de Campos}

Antes de procedermos à análise dos acidentes de trabalho nas plataformas de petróleo na Bacia de Campos, iremos caracterizar as condições de trabalho nas mesmas.

De acordo com um dossiê elaborado pelo SINDIPETRO-NF (1997) sobre condições de trabalho na Bacia de Campos, em 1997 estimavase que havia cerca de 6.000 trabalhadores em atividade. Deste total, uma proporção muito maior era de empregados de empresas contratadas e que estariam em condições gerais de jornada, salário, comunicação com a costa, de transporte e hospedagem piores do que o pessoal efetivo da empresa responsável pela exploração.

As condições de trabalho nas plataformas envolvem, além do confinamento, o trabalho em turnos de 12 horas pelo dia e pela noite, alternadamente durante o mesmo período de embarque, prejudicando seriamente o estabelecimento de um ritmo de sono/vigília adequado à total recuperação do trabalhador para o reinício da sua jornada de trabalho (SINDIPETRO-NF, 1997). Por exemplo, a carga horária do operador de produção embarcado é de 12 horas de trabalho/dia, durante 14 dias, resultando no que os trabalhadores chamam de "virada", no sétimo dia de embarque (nesse dia as equipes que estão "virando" trabalham em torno de 18 horas), quando se faz a troca de turno do dia com a noite (Pessanha, 1994).

Em relação ao regime de trabalho e descanso, o mesmo é de 14/21 dias para os trabalhadores diretos e de 14/14 dias para os trabalhadores terceirizados. Mesmo os trabalhadores diretos não se consideram satisfeitos com o atual regime. Pesquisa realizada por Pessanha (1994) com trabalhadores embarcados na Bacia de Campos aponta a defesa quase unânime de um regime de 10/20 dias.

Quanto às condições de alojamento, em muitas plataformas, os trabalhadores terceirizados, em vez de residirem nos camarotes como os trabalhadores diretos, são alocados em conjuntos de três ou quatro containers e um banheiro colocados sobre o convés, designados Módulos Temporários de Alojamento que acabam se tornando permanentes (Sevá Filho, 2000).

O panorama atual é de ampliação intensa do volume de operações e de instalações e suas interligações, acelerando a complexidade e a interdependência dos desempenhos e dos incidentes nas diversas partes deste sistema produtivo. Até hoje foram investidos 17 bilhões de dólares na exploração e produção de petróleo nesta região. A produção média é de 850.000 barris/dia (cerca de $75 \%$ da produção nacional), com o Brasil chegando em 1997 a entrar no seleto grupo dos países que produzem mais de 1.000.000 barris/dia, e de 15 milhões de metros cúbicos de gás natural (aproximadamente $50 \%$ da produção nacional) (Jornal do Brasil, 20/06/99). Neste processo vem ocorrendo a utilização intensiva e simultânea de instalações antigas e novas. Todo o sistema vem sendo pressionado a cumprir performances de pico, operando nos limites de sua capacidade instalada e de vida útil (SINDIPETRO-NF, 1997). A degradação média das instalações físicas tem avançado em ritmo mais intenso do que a depreciação projetada de tais equipamentos e sistemas, pois não se tem priorizado a manutenção preventiva nem a reforma estrutural de instalações de alto risco (Sevá Filho, 2000). Este quadro se agrava à medida que não são realizados alguns procedimentos cruciais para o rigor na prevenção de acidentes, tais como: vistorias e inspeções; certificação e calibração de equipamentos e instrumentos; medições de corrosão, de integridade de materiais e da geometria de peças; perícias após deformação, fratura, ou rompimento de peças; e mensurações químicas, físicas e ambientais não são realizados (Sevá Filho, 2000).

Esta ampliação e intensificação da capacidade produtiva vem sendo acompanhada da redução de efetivos de trabalhadores, intensificação do trabalho e exigiência de polivalência. A prática da redução do quadro próprio de funcionários se deu notadamente a partir da segunda metade da década de 80 .

Dados referentes ao total de trabalhadores embarcados em seis plataformas na Bacia de Campos entre 1989 e 1992 demonstram uma 
redução média de aproximadamente 25\% (Pessanha, 1994). Em relação à polivalência, a perspectiva atual da empresa é que estas mudanças sejam etapas intermediárias na busca do chamado operador mantenedor, ou seja, trabalhadores que além de supervisionar e controlar as variabilidades presentes na operação, também intercedam na manutenção do sistema, parcial ou totalmente, com base na indicação dos pontos de defeitos acusados pelo sistema de controle (Pessanha, 1994). Todo este processo de redução de efetivos e polivalência tem na prática resultado na intensificação do trabalho, contribuindo para ampliar os riscos de incidentes e acidentes.

Estatísticas da própria empresa citadas pelo dossiê do SINDIPETRO-NF (1997) demonstram ser o setor de exploração e produção o que apresenta a maior freqüência de acidentes de trabalho. Em 1995, a taxa de freqüência de acidentes na exploração e produção foi de 16,7 , contra 13,3 no refino, a segunda maior taxa, sendo a média da empresa 11,9. Em 1996, a taxa foi de 17,3 na exploração e produção, ficando a segunda maior freqüência com a engenharia $(16,6)$, contra a média da empresa de 14,7 . As estatísticas também mostram uma distribuição claramente diferenciada dos riscos entre os trabalhadores diretos e os terceirizados nas plataformas de petróleo. Por exemplo, dados nacionais da empresa, em 1996, registram uma taxa de freqüência de acidentes com afastamento de 10,6 para os trabalhadores próprios e uma de 17,3 para a mão de obra contratada.

Os dados disponibilizados pelo Ministério da Previdência e Assistência Social (MPAS), fundamentados no estudo realizado por Ávila \& Castro (1998) sobre o ano de 1996, que adotam uma metodologia mais moderna para o cálculo de indicadores, revelam que o setor de extração de petróleo e gás natural possuía um total de 2.143 trabalhadores vinculados, com 866 acidentes de trabalho registrados, sendo 781 típicos. Tanto o índice de freqüência $(42,86)$, quanto o de gravidade $(25,18)$ foram estimados pelos autores como os maiores deste ano dentre todos os setores, segundo a Classificação Nacional de Atividades Econômicas, confirmando a importância, em termos de riscos à saúde dos trabalhadores, do setor de extração de petróleo e gás natural.

Em termos de números absolutos, os dados nacionais do ano de 1996, disponibilizados pela Secretaria de Segurança e Saúde no Trabalho/Ministério do Trabalho (SSST/MTb) com base em dados brutos de benefícios concedidos pelo Instituto Nacional de Seguridade Social (INSS/MPAS), referentes ao grupo de ativi- dade econômica Extração de Petróleo e Serviços Correlatos, indicam a ocorrência de 203 acidentes com afastamento superior a 15 dias, 27 acidentes que provocaram incapacidade parcial permanente, três acidentes que provocaram invalidez permanente e três acidentes fatais (Anuário Brasileiro de Proteção, 1999).

Para o ano de 1998, trabalho realizado por Bartolotti (1999) nas plataformas da Bacia de Campos revela a ocorrência de nove óbitos em acidentes de trabalho (um trabalhador direto, sete trabalhadores terceirizados e um sem informação).

Embora de difícil compatibilização e comparação, considerando-se também a fragilidade das estatísticas oficiais, que não representam a real dimensão do quadro de acidentes relacionado com a exploração de petróleo, os dados citados anteriormente apontam para um grave quadro de acidentes de trabalho neste setor.

Tipos de eventos, sistema envolvido e modo de operação

\section{- Panorama geral dos incidentes/acidentes}

De acordo com a Tabela 2, no período compreendido, verifica-se a ocorrência do total de 64 eventos. Destes, 51 corresponderam a acidentes, 10 a incidentes e três a eventos sobre os quais não havia informações que permitissem defini-los como acidentes ou incidentes.

Os 51 acidentes ocorridos resultaram em 41 trabalhadores lesionados, e o total dos acidentes que resultaram em lesões foi de 27 (53\% do total), o que corresponde à média de 1,5 trabalhador lesionado em cada acidente que tenha resultado em lesões. Do universo de acidentes com lesões, seis $(11,8 \%)$ resultaram em mais de um trabalhador lesionado, totalizando $20 \mathrm{e}$ correspondendo a $48,8 \%$ do total, expressando o grande potencial de acidentes com múltiplos trabalhadores afetados. Do total de 41 trabalhadores acidentados, 29 (71\%) eram de empresas prestadoras de serviço. Quanto aos demais, 10 eram trabalhadores próprios e dois não tiveram a empresa a que pertenciam identificada.

Em relação ao tipo de acidente, do total de 51 acidentes, $20(39,2 \%)$ corresponderam a eventos envolvendo quedas de trabalhadores e materiais, bem como rompimentos de cabos corroídos e mangueiras, resultando no total de $22(53,7 \%)$ trabalhadores lesionados. Dentre estes 17 (77\%) eram de empreiteiras e cinco (23\%) da própria empresa. De acordo com estes dados, para cada trabalhador da empresa acidentado com lesão, houve uma média de 3,4 de empreiteiras na mesma situação. 
Distribuição dos incidentes/acidentes nas plataformas de petróleo. Bacia de Campos, Rio de Janeiro entre 18/08/95 e 14/04/97.

\begin{tabular}{|c|c|c|c|c|c|c|c|}
\hline \multirow[t]{2}{*}{ Tipo de Incidente/Acidente } & \multicolumn{2}{|c|}{ Eventos } & \multicolumn{2}{|c|}{$\begin{array}{l}\text { Acidentes com } \\
\text { trabalhadores lesionados }\end{array}$} & \multicolumn{3}{|c|}{$\begin{array}{l}\text { Total de trabalhadores } \\
\text { lesionados }\end{array}$} \\
\hline & $\mathrm{n}$ & $\%$ & $\mathrm{n}$ & $\%$ & $n$ & $\mathrm{P} / \mathrm{T} 1$ & $\%$ \\
\hline Acidentes & 51 & 79,7 & 27 & 100 & 41 & & 100 \\
\hline Quedas e rompimento de material & 20 & 39,2 & 20 & 74,1 & 22 & $5 / 17$ & 53,72 \\
\hline Vazamentos & 17 & 33,3 & 1 & 3,7 & 5 & $2 / 3$ & 12,2 \\
\hline Incêndios & 9 & 17,7 & 1 & 3,7 & 6 & $1 / 5$ & 14,6 \\
\hline Choques elétricos & 2 & 3,9 & 2 & 7,4 & 2 & $2 / 0$ & 4,9 \\
\hline Ausência de dados 3 & 3 & 5,9 & 3 & 11,1 & $6^{4}$ & $0 / 4$ & 14,65 \\
\hline Incidentes & 10 & 15,6 & & & & & \\
\hline Não definidos & 3 & 4,7 & & & & & \\
\hline Total & 64 & 100 & & & & & \\
\hline
\end{tabular}

$1 \mathrm{P}=$ Trabalhadores próprios, $\mathrm{T}=$ Trabalhadores de empresas terceirizadas.

2 Dos 20 acidentes, dois tiveram dois trabalhadores lesionados em cada um.

3 Para estes casos os dados permitiram apenas a classificação do evento como acidente, sem permitir a identificação do tipo.

4 Para o caso de um acidente que lesionou dois trabalhadores foi impossível identificá-los como trabalhadores próprios ou de empresas terceirizadas.

5 Dos três acidentes, um teve dois trabalhadores lesionados e outro teve três trabalhadores lesionados.

O segundo tipo de acidente mais freqüente foram os vazamentos de substâncias, totalizando 17 (33,3\%) das ocorrências (Tabela 2). O número de trabalhadores lesionados nesse tipo de acidente foi cinco (12,2\%), todos em um único evento. Em seguida, vêm os incêndios, que corresponderam a nove $(17,7 \%)$ ocorrências e resultaram em seis $(14,6 \%)$ trabalhadores lesionados.

Dos 10 incidentes, a maioria se deu por falhas de equipamentos e queda de geração de energia. Deve-se frisar que estes incidentes constituem apenas a ponta do iceberg dos riscos que existem atualmente nas plataformas de petróleo da Bacia de Campos. A queda de energia pode, em muitos casos, resultar em paradas das operações e, por conseguinte, na necessidade de novas partidas, resultando no que Magrinni (comunicação pessoal) denomina de momento crítico, ou seja, situações em que há uma potencialização dos riscos de acidentes. Por outro lado, as falhas nos equipamentos denotam a degradação dos mesmos.

\section{- Distribuição dos incidentes/acidentes nas plataformas de petróleo pelo sistema envolvido}

De acordo com a Tabela 3, $22(34,4 \%)$ dos incidentes/acidentes ocorreram em operações físicas. Deste total, mais da metade $(n=13)$ estiveram relacionados à operação dos poços. Cor- te/solda e bombeamento de líquido/compressão de gases totalizaram três cada um.

É interessante observar que incidentes/acidentes para os quais não foi possível definir o sistema envolvido vêm em segundo lugar, com $21(32,8 \%)$ eventos. Logo após, aparecem as unidades auxiliares, totalizando 14 (32,6\%) dos incidentes/acidentes, sendo os dois principais o sistema flare $(\mathrm{n}=5)$ e o sistema de suprimento de energia $(n=6)$. Em seguida, constam as operações com guindaste (levantamento mecânico de cargas), com o percentual de 7,8\% $(\mathrm{n}=5)$ em relação ao total de incidentes/acidentes.

É importante notar que, embora na Tabela 3 os sistemas apareçam separados de modo a permitir sua classificação, na prática se encontram altamente interconectados de modo que um evento que se inicie em qualquer um dos mesmos, pode rapidamente se propagar por outros, conformando o chamado efeito dominó, podendo resultar em múltiplos danos e verdadeiras catástrofes.

\section{- Distribuição dos incidentes/acidentes nas plataformas de petróleo pelo modo de operação envolvido}

Na Tabela 4 podemos verificar o modo de operação em que os incidentes/acidentes ocorreram, destacando-se as atividades de operação normal, com 23 casos (36\%). Em seguida se en- 
Tabela 3

Distribuição dos incidentes/acidentes nas plataformas de petróleo por sistema envolvido. Bacia de Campos, Rio de Janeiro entre 18/08/95 e 14/04/97.

\begin{tabular}{|c|c|c|}
\hline Sistema envolvido & $\mathbf{n}$ & $\%$ \\
\hline Operações físicas ${ }^{1}$ & 22 & 34,4 \\
\hline Ligadas à operação dos poços & 13 & \\
\hline Corte e solda & 3 & \\
\hline Bombeamento de líquido/compressão de gases & 3 & \\
\hline Resfriamento/aquecimento & 2 & \\
\hline Drenagem & 1 & \\
\hline $\begin{array}{l}\text { Equipamentos de armazenamento associados } \\
\text { (cilindros e depósitos pressurizados) }\end{array}$ & 1 & 1,6 \\
\hline Unidades auxiliares² & 14 & 21,8 \\
\hline Sistema Flare & 5 & \\
\hline Sistema de suprimento de energia & 4 & \\
\hline Sistema de bombas de incêndio & 1 & \\
\hline Sistema de água potável & 1 & \\
\hline Sistema de vapor - circulação de água quente & 1 & \\
\hline Operações com guindaste & 5 & 7,8 \\
\hline Ancoragem & 1 & 1,6 \\
\hline Indefinido & 21 & 32,8 \\
\hline Total & 64 & 100 \\
\hline
\end{tabular}

Tabela 4

Distribuição dos incidentes/acidentes nas plataformas de petróleo pelo modo de operação envolvido. Bacia de Campos, Rio de Janeiro entre 18/08/95 e 14/04/97.

\begin{tabular}{lrc}
\hline Modo de operação & $\mathbf{n}$ & $\%$ \\
\hline Operação normal & 23 & 36 \\
Trabalho de manutenção/modificação & 16 & 25 \\
Carregamento/descarregamento, transferência & 2 & 3,1 \\
Teste & 3 & 4,7 \\
Partida após modificação/manutenção & 2 & 3,1 \\
Parada & 2 & 3,1 \\
Emergência & 1 & 1,6 \\
Início das atividades & 1 & 1,6 \\
Indefinido & 14 & 21,8 \\
Total & 64 & 100 \\
\hline
\end{tabular}

contram os ocorridos durante atividades de manutenção/modificação, totalizando 16 (25\%). Há um elevado número de eventos para os quais não foi possível definir o modo de operação, atingindo um percentual de $21,8 \%(n=14)$.

\section{Análise das causas dos acidentes}

As formas de classificar as causas dos acidentes traduzem, inevitavelmente, um determinado recorte no modo de identificá-las, analisálas e propor estratégias de controle e prevenção. Por exemplo, de acordo com os dados da própria empresa referentes a 231 acidentes ocorridos entre janeiro e agosto de 1996, 72,3\% foram classificados tendo como causa básica "atos inseguros". Esta tendência de se atribuir aos próprios trabalhadores a responsabilidade pelos acidentes em que são vítimas, uma forma bastante simplificada de análise e classificação, tem nos últimos anos mudado na Europa, conforme afirma Wisner (1994), permanecendo ainda no Brasil como uma das formas de controle social dos trabalhadores. Com o objetivo de possibilitar uma análise mais aprofundada, utilizamos como referência o MARS, uma vez que além de não se limitar às causas imediatas, incluindo também as subjacentes, amplia a análise multicausal, relacionando-a diretamente ao contexto do processo de trabalho. É importante destacar que, para cada acidente analisado, podem ser atribuídas várias causas, principalmente as subjacentes, já que um acidente, dentro da abordagem sistêmica e sóciotécnica adotada, é conseqüência de um conjunto de decisões e ações ao longo do tempo que acabam por conjugarem-se no evento final propriamente dito, ou seja, o acidente (Machado et al., 2000).

No contexto dessa abordagem, de acordo com a Tabela 5, os erros dos operadores aparecem como causa imediata em apenas $10 \%$ dos eventos. Nos métodos de análises desenvolvidos para sistemas complexos, como é o caso das plataformas de petróleo, há maior ênfase nas falhas de componentes estruturais do processo de produção, que, de acordo com a Tabela 5 , aparecem em $86 \%$ das causas imediatas, estando relacionadas às falhas de componentes e corrosão de equipamentos.

Ao analisarmos as causas subjacentes na Tabela 6, as omissões gerenciais/organizacionais estiveram presentes em $69,6 \%$ dos eventos e a inadequacidade do projeto em $26,1 \%$, totalizando ambas 95,7\% dos eventos. Procedimentos apropriados não seguidos aparecem em apenas $4 \%$ dos eventos e mesmo assim podem e devem ser relativizados pela priorização da 
produção em relação à segurança, contribuindo para que em muitos casos as atividades de manutenção com riscos de acidentes sejam realizadas com a produção em andamento.

\section{Discussão}

Ainda que o próprio processo em que se deu a investigação dos acidentes nas plataformas de petróleo tenha contribuído para limitar a coleta de informações, a forma em que tratamos e analisamos os dados revelam diversos aspectos que consideramos importantes de serem discutidos.

$\mathrm{O}$ atual quadro das condições de trabalho e segurança nas plataformas revela uma situação bastante degradada, envolvendo não só o potencial de aumento na freqüência dos acidentes para os trabalhadores, sobretudo os terceirizados, mas também na gravidade, podendo um acidente resultar em múltiplos óbitos.

Quanto ao aumento da freqüência, em especial no que se refere aos trabalhadores terceirizados, convém observar que a maioria envolveu quedas de trabalhadores e materiais, bem como rompimentos de cabos corroídos e mangueiras, resultando em mais da metade dos trabalhadores lesionados, predominando trabalhadores de empreiteiras. Estes acidentes tendem a expressar tanto a degradação de equipamentos, como também das atividades laborativas, que são por vezes agravadas num ambiente de trabalho extremamente compactado e com pouca atenção às necessidades de permanente limpeza e desobstrução das áreas de trabalho. Quanto à limpeza, cumpre também observar que alguns acidentes ocorreram em decorrência de quedas causadas por tropeços em materiais e escorregões em locais cheios de óleo no chão.

No que se refere ao modo de operação, 25\% ocorreram em atividades de manutenção/modificação, sendo estas, de um modo geral, as principais atividades terceirizadas e que empregam o maior número de trabalhadores. Destes acidentes, para os quais foi possível identificar as conseqüências, encontrou-se um total de 17 trabalhadores acidentados, sendo quatro diretos e $13(76,4 \%)$ terceirizados. Tal conclusão é também corroborada tanto pelo estudo de Rundmo (1994), que identificou que os trabalhos de reparo e manutenção preventiva, em sua quase totalidade desenvolvidas por trabalhadores terceirizados, foram as atividades com maior número de acidentes, como pelo relatório da OIT (1993), para o qual a maioria das estatísticas revela uma incidência muito maior

\begin{tabular}{|c|c|c|}
\hline \multicolumn{3}{|c|}{$\begin{array}{l}\text { Causas imediatas identificadas no universo de } 64 \text { incidentes/acidentes ocorridos } \\
\text { nas plataformas de petróleo de acordo com a classificação adotada pelo Major } \\
\text { Accident Reporting System. Bacia de Campos, Rio de Janeiro entre 18/08/95 } \\
\text { e 14/04/97. }\end{array}$} \\
\hline \multirow{2}{*}{$\begin{array}{l}\text { Tipos de causa imediatas } \\
\text { Erros do operador }\end{array}$} & \multicolumn{2}{|c|}{ Número de causas } \\
\hline & 5 & $10 \%$ \\
\hline Manutenção & 3 & \\
\hline Construção & 1 & \\
\hline Movimentação de carga & 1 & \\
\hline Falhas de componentes & 35 & $70 \%$ \\
\hline $\begin{array}{l}\text { Transporte por tubulações } \\
\text { ou seus elementos (bombeamento) }\end{array}$ & 6 & \\
\hline Válvulas & 12 & \\
\hline Equipamentos principais & 1 & \\
\hline Bombas & 4 & \\
\hline Compressores/gás comprimido & 1 & \\
\hline Instrumentos e componentes de instrumentação & 4 & \\
\hline Componentes elétricos & 5 & \\
\hline Trava de segurança-tambor de freio (guindaste) & 2 & \\
\hline Corrosão & 8 & $16 \%$ \\
\hline Eventos internos não conectados com a instalação & 2 & $4 \%$ \\
\hline Total 1 & 50 & $100 \%$ \\
\hline $\begin{array}{l}\text { Fonte: Freitas et al., } 1997 \text {. } \\
1 \text { O número total de causas imediatas é menor que o n } \\
\text { incidentes/acidentes devido ao fato de, por falta de da } \\
\text { realizar a identificação para todos. }\end{array}$ & ter si & Dossível \\
\hline
\end{tabular}

entre estes trabalhadores, os quais realizam a maioria das atividades mais perigosas ao mesmo tempo em que possuem menor capacitação, treinamento e direitos.

No que se refere ao aumento da gravidade e do potencial de eventos com múltiplas vítimas, podendo em alguns casos chegar a conseqüências catastróficas, deve-se observar que em apenas seis acidentes encontram-se 20 trabalhadores lesionados, ou seja, quase a metade, demonstrado o potencial de acidentes com múltiplas vítimas. Por sua vez, metade dos acidentes envolveram vazamentos e incêndios, cujas características envolvem tanto o potencial de danos à saúde a médio e a longo prazo, como o risco de resultarem em eventos catastróficos como os acidentes nas plataformas de Enchova (no Brasil, em 1984) e Piper-Alpha (no Reino Unido, em 1988).

Ainda em relação ao potencial de acidentes catastróficos, importa observar que $34,4 \%$ dos eventos ocorridos na Bacia de Campos estiveram relacionados às operações físicas, sendo 
Causas subjacentes identificadas no universo de 64 incidentes/acidentes ocorridos nas plataformas de petróleo de acordo com a classificação adotada pelo Major Accident Reporting System. Bacia de Campos, Rio de Janeiro, entre 18/08/95 e 14/04/97.

\begin{tabular}{|c|c|c|}
\hline \multirow{2}{*}{$\begin{array}{l}\text { Tipos de causa subjacentes } \\
\text { Omissões gerenciais/Organizacionais }\end{array}$} & \multicolumn{2}{|c|}{ Número de causas } \\
\hline & 64 & $69,6 \%$ \\
\hline Ausência de cultura de segurança & 1 & \\
\hline Organização de segurança inadequada & 1 & \\
\hline $\begin{array}{l}\text { Procedimentos de segurança pré-determinados } \\
\text { não observados }\end{array}$ & 4 & \\
\hline Procedimentos insuficientes/obscuros & 25 & \\
\hline Operação & 4 & \\
\hline Manutenção & 12 & \\
\hline Testes, autorizações, inspeção ou calibração & 3 & \\
\hline Permissões de trabalho & 4 & \\
\hline Armazenamento de material & 1 & \\
\hline Não definido & 1 & \\
\hline Supervisão insuficiente & 5 & \\
\hline Treinamento insuficiente do operador & 3 & \\
\hline Subcontratados & 21 & \\
\hline Instalações de segurança insuficientes & 4 & \\
\hline Inadequacidade do projeto & 24 & $26,1 \%$ \\
\hline $\begin{array}{l}\text { Aplicação de códigos/práticas não sustentáveis } \\
\text { para o processo }\end{array}$ & 7 & \\
\hline $\begin{array}{l}\text { Processo analisado inadequadamente do ponto } \\
\text { de vista da segurança de modo que perigos } \\
\text { não tenham sido identificados }\end{array}$ & 7 & \\
\hline Erro de projeto & 9 & \\
\hline $\begin{array}{l}\text { Falha na aplicação de princípios ergonômicos } \\
\text { no projeto da interface homem-máquina }\end{array}$ & 1 & \\
\hline Procedimentos apropriados não seguidos & 4 & $4,3 \%$ \\
\hline Procedimentos relacionados à manutenção & 2 & \\
\hline $\begin{array}{l}\text { Procedimentos relacionamentos a testes, a autorizações, } \\
\text { à inspeção ou à calibração }\end{array}$ & 2 & \\
\hline Total 1 & 92 & $100 \%$ \\
\hline
\end{tabular}

1 O número total de causas subjacentes é maior que o número total de incidentes/ acidentes devido ao fato de para vários acidentes terem sido identificadas mais de uma causa.

\section{Conclusão}

Neste artigo objetivamos demonstrar tanto o potencial de risco existente na atividade de exploração marítima de petróleo, quanto a sua gravidade nas condições existentes no Brasil, particularmente na Bacia de Campos. Tais condições ressaltam os conflitos existentes entre o gerenciamento de riscos e o gerenciamento da produção, a segurança e as características da terceirização, que tendem a aumentar o perigo para os trabalhadores, não somente daqueles terceirizados nas atividades de manutenção, mas também para o conjunto dos trabalhadores das plataformas, frente aos riscos de acidentes ampliados.

$\mathrm{O}$ fato de a maioria dos trabalhadores acidentados serem terceirizados expressa a tendência mundial de constituírem de dois terços a três quartos do total da mão de obra empregada nas plataformas. Como estratégia gerencial, tem como principal objetivo a redução de custos operacionais fixos mediante a redução do efetivo de trabalhadores diretos com intensificação do seu trabalho e exigência de polivalência e da contratação de mão-obra precarizada em seus direitos sociais, com salários mais baixos e, na maioria dos casos, desqualificada, de modo a possibilitar a maximização dos lucros financeiros (OIT, 1993). Esta estratégia gerencial tem implicações diretas na organização do trabalho nas plataformas, que são normalmente caracterizadas por uma ampla diversidade de atividades, passando a incluir também uma multiplicidade de empresas e de gestão do trabalho envolvendo um grande número de trabalhadores em regime de subcontratação; trabalhadores que atuam no ambiente confinado das plataformas, tendo de mudar continuamente de local e de atividade de trabalho (Sutherland, 1991).

Toda a organização do trabalho e o gerenciamento da produção e dos riscos nas plataformas da Bacia de Campos têm sido direcionados para o aumento da produção e dos lucros, por meio da ampliação do volume de operações, de instalações e de suas interligações, com a utilização intensiva e simultânea de instalações. Muitas destas operam nos limites de sua capacidade instalada e vida útil, o que envolve milhares de trabalhadores, tendo como resultado o potencial de ampliação e agravamento dos riscos à saúde e à vida dos mesmos. Para os trabalhadores diretos, os riscos se ampliam e se agravam por meio de uma maior carga de trabalho e desgaste resultantes da redução do efetivo, além da exigência da polivalência. Para os trabalhadores terceirizados, os 
principais atingidos quando comparados com os trabalhadores diretos das empresas, os riscos se agravam e se ampliam pelo fato de receberem não somente menos treinamento e informação de segurança e saúde, mas também de trabalharem em condições mais precárias. Neste contexto gerencial e organizacional estão dadas as condições não só para um aumento na freqüência dos acidentes, mas também, como aponta Paté-Cornell (1993), para a geração de novas catástrofes como a de Piper-Alpha.

Este quadro referente aos aspectos relacionados à organização do trabalho e ao gerenciamento da produção, com implicações diretas sobre os riscos de acidentes, relaciona-se diretamente com o nosso objetivo de contribuir para alterar a lógica de análise dos acidentes no país, em especial, tomando-se por base as AVST. Este artigo é apenas um exemplo de como pode ser promissor e quanto é dura a batalha de incorporação de novas técnicas de investigação de acidentes que sejam contextualizadas, incorporando os aspectos gerenciais e organizacionais que se encontram na origem dos acidentes e incluindo a ampliação da participação e do saber dos trabalhadores. Um dos resultados deste tipo de análise de acidentes é a necessária visibilidade e transparência, que exigem sociedades democráticas, nas questões relacionadas à produção, saúde e segurança de instituições fechadas e poderosas do mundo do trabalho, como no caso das empresas de petróleo.

O fortalecimento da capacidade das ações de controle público dos acidentes de trabalho exige também que as AVST incorporem os avanços da moderna acidentologia, presente no movimento mundial de controle dos acidentes ampliados, na Convenção sobre a Prevenção de Acidentes Ampliados da OIT (Convenção 174), e no desenvolvimento gradativo de programas intersetoriais envolvendo seções da Saúde, do Trabalho, do Meio Ambiente e da Previdência Social, nos vários níveis de governo - federal, estadual e municipal.

Por outro lado e simultaneamente, uma das conclusões mais importantes a que chegamos ao reanalisarmos os dados de acidentes das plataformas na Bacia de Campos, é a necessidade imediata da empresa rever sua metodologia de análise de acidentes. A forma de analisar os acidentes deve servir para avaliar e redefinir as políticas de segurança das empresas, e está intrinsicamente ligada ao gerenciamento de riscos exercido pela empresa, fazendo parte de sua política gerencial e organizacional mais geral, assim como de sua cultura técnica de saúde e segurança.
Dentro da perspectiva de análise sócio-técnica e participativa assumida neste artigo, o controle e a prevenção dos acidentes deve incluir mudanças de políticas gerenciais e organizacionais, assim como de culturas técnicas fechadas à participação dos trabalhadores e da sociedade em geral. Um dos condicionantes para estas mudanças envolve um amplo debate entre as empresas de exploração do petróleo com os trabalhadores e os órgãos públicos, que é um dos papéis a ser assumido pelas próprias AVST. Entretanto, o caso em questão demonstra a dificuldade para este papel ser posto em prática, em decorrência de uma política gerencial que obstaculiza de forma sistemática tanto as AVST, como uma relação mais aberta e democrática com os trabalhadores.

O poder econômico e político da empresa na região faz com que a potencial contribuição de órgãos relacionados com a saúde do trabalhador só se efetive após passar por um filtro legalista, distanciador e com baixa capacidade de mobilização para mudanças culturais e gerenciais. Dessa forma, as fiscalizações e inspeções, que poderiam trazer uma ênfase à vigilância da saúde e à segurança no trabalho sob a perspectiva da saúde coletiva, acabam por serem digeridas de forma a se comportar nos mesmos moldes da gestão da empresa. Nesse contexto, as autoridades sanitárias e suas práticas de vigilância são bastante restringidas e esporádicas, o que poderia ser revertido pelo sinergismo de ações inter-institucionais com a participação dos trabalhadores. O exemplo do artigo, contudo, mostra a dificuldade de serem integradas ações de instituições que atuam com lógicas individuais e isoladas. A falta de políticas públicas intersetoriais na área reforça a fragmentação, um dos pilares da vulnerabilidade institucional brasileira no campo da saúde dos trabalhadores.

Neste artigo intentamos contribuir para as AVST não só revelando a gravidade das condições de trabalho e segurança nas plataformas, mas também demonstrando a importância de se adotarem abordagens de investigação que, ao apontarem os condicionantes gerenciais e organizacionais dos acidentes, superem os limites das abordagens que culpabilizam os trabalhadores e restringem a participação mais efetiva dos mesmos, como ferramenta de grande potencial tanto para o gerenciamento de riscos no "chão-da-fábrica", como para formulação de políticas públicas mais amplas no seu escopo e impacto. 


\section{Referências}

ANDERSSON, R., 1991. The Role of Accidentology in Occupational Injury Research. Ph.D. Thesis, Sundbyberg: Department of Social Medicine, Karolinska Institute.

ANUÁRIO BRASILEIRO DE PROTEÇÃO, 1999. Edição Especial de 99. Porto Alegre: Editora MPF Publicações.

ÁVILA, J. B. C. \& CASTRO, M. C., 1998. Metodologia para Cálculo de Indicadores de Acidente de Trabalho e Critérios para Avaliação do Enquadramento dos Ramos de Atividade Econômica por Grau de Risco - 1996. Brasília, DF: Ministério da Previdência e Assistência Social.

BACKSTRÖM, T. \& DÖÖS, M., 1995. The Riv Method. A Participative Risk Analysis: Method and Its Application. Stockholm: Swedish Institute for Work Life Research.

BARTOLOTTI, L. R. A., 1999. Óbitos Ocorridos na Bacia de Campos em 1998 - Um Breve Histórico. Rio de Janeiro: Sindicato dos Petroleiros do Norte Fluminense. (mimeo.)

BOOTH, M. \& BUTLER, J., 1992. A new approach to permit to work systems offshore. Safety Science, 15:309-320.

CAMACHO, M. \& ALMEIDA, R., 1997. Jorro milionário Petrobrás bate recorde e chega, em dezembro, a marca de 1 milhão de barris por dia. Veja, 1525: 108-110.

DROGARIS, G., 1992. Major Accident Reporting System - Lessons Learned from Accidents Notified. London: Elsevier.

DWYER, T., 1991. Life and Death at Work - Industrial Accidents as a Case of Socially Produced Error. New York: Plenum.

FERREIRA, L. L. \& IGUTI, A. M., 1996. O Trabalho dos Petroleiros - Perigoso, Complexo, Contínuo e Coletivo. São Paulo: Prefeitura Municipal de Santos/ Editora Scritta/Federação Única dos Petroleiros.

FREITAS, C. M., 1996. Acidentes Industriais Ampliados Incorporando a Dimensão Social nas Análises de Riscos. Tese de Doutorado, Rio de Janeiro: Escola Nacional de Saúde Pública da Fundação Oswaldo Cruz.

KLETZ, T., 1993. Lessons From Disaster - How Organizations Have on Memory and Accidents Recur. London: Institution of Chemical Engineers.

LEPLAT, J. \& TERSSAC, G., 1990. Les Facteurs Humains de la Fiabilité dans les Systemes Complexes. Paris: Ministére de la Recherche et la Technologie.

LORRY, M., 1999. Acidentes Industriais - O Custo do Silêncio. Rio de Janeiro: MultiMais Editoria.

MACHADO, J. M. H., 1996. A Heterogeneidade da Intervenção: Alternativas e Processos de Vigilância em Saúde do Trabalhador. Tese de Doutorado, Rio de Janeiro: Escola Nacional de Saúde Pública, Fundação Oswaldo Cruz.

MACHADO, J. M. H.; PORTO, M. F. S. \& FREITAS, C. M., 2000. Perspectivas para uma análise interdisciplinar e participativa de acidentes (AIPA) no contexto da Indústria de Processo. In: Acidentes Industriais Ampliados - Desafios e Perspectivas para o Controle e a Prevenção. (C. M. Freitas, M. F. S. Porto \& J. M. H. Machado, org.), pp. 49-81, Rio de Janeiro: Editora Fiocruz.

MENCKEL, E. \& KULLINGER, B., 1996. Fifteen Years of Occupational-Accident Research in Sweden. Stockholm: Swedish Council for Work Life Research.

MESHKATI, N., 1991. Human factors in large-scale technological systems' accidents: Three mile island, Bhopal,
Chernobyl. Industrial Crisis Quarterly, 5:133-154.

OIT (Organización Internacional del Trabajo), 1993. Seguridad del Trabajo en Instalaciones Petrolíferas en el Mar y Asuntos Conexos. Ginebra: Oficina Internacional del Trabajo.

PATÉ-CORNELL, M. E., 1993. Learning from the piper alpha accident: A postmortem analysis of technical and organizational factors. Risk Analysis, 13: 215-232.

PESSANHA, R. M., 1994. O Trabalho Off Shore - Inovação Tecnológica, Organização do Trabalho e Qualificação do Operador de Produção na Bacia de Campos, RJ. Dissertação de Mestrado, Rio de Janeiro: Coordenação dos Programas de Pós-Graduação de Engenharia, Universidade Federal do Rio de Janeiro.

PERROW, C., 1984. Normal Accidents - Living with High-Risk Technologies. New York: Basic Books.

PORTO, M. F. S., 1994. Trabalho Industrial, Saúde e Ecologia - Avaliação Qualitativa de Riscos Industriais com Dois Estudos de Caso na Indústria Química. Tese de Doutorado, Rio de Janeiro: Coordenação dos Programas de Pós-Graduação de Engenharia, Universidade Federal do Rio de Janeiro.

RASMUSSEN, K., 1995. The Experience with the Major Accident Reporting System - From 1984 to 1993. Luxembourg: Office for Official Publications of the European Communities.

RUNDMO, T., 1992. Risk perception and safety on offshore petroleum platforms - Part I: Perception of risk. Safety Science, 17:39-52.

RUNDMO, T., 1994. Occupational accidents and objective risk on north sea offshore installations. Safety Science, 17:103-116.

SEVÁ FILHO, A. O. S., 2000. "Seguuura, peão" - Alertas sobre o risco técnico coletivo crescente na indústria petrolífera (Brasil, anos 1990). In: Acidentes Industrial Ampliados - Desafios e Perspectivas para o Controle e a Prevenção (C. M. Freitas, M. F. S. Porto \& J. M. H. Machado, org.), pp. 169-196, Rio de Janeiro: Editora Fiocruz.

SINDIPETRO-NF (Sindicato dos Petroleiros do Norte Fluminense), 1997. Os Subterrâneos da Bacia-As Mortes, os Riscos e a Ilegalidade na Exploração e Produção de Petróleo da Bacia de Campos (Dossiê do Sindicato dos Petroleiros do Norte Fluminense para a Comissão Parlamentar de Inquérito que Apura "Falta de Segurança e Condições de Trabalho nas Plataformas Petrolíferas do Estado do Rio de Janeiro"). Macaé: SINDIPETRO-NF.

SUTHERLAND, V. \& COOPER, C. L., 1991. Occupational stress and accidents offshore. In: Proceedings of the First International Conference on Health, Safety and Environment in Oil and Gas Exploration and Production, v. 1, p. 835. Haya: International Conference on Health, Safety and Environment in Oil and Gas Exploration and Production.

WISNER, A., 1994. O trabalhador diante dos sistemas complexos e perigosos. In: A Inteligência no Trabalho: Textos Selecionados de Ergonomia. (A. Wisner, ed.), pp. 53-70, São Paulo: FUNDACENTRO.

WOOLFSON, C.; FOSTER, J. \& BECK, M., 1996. Paying for the Piper-Capital and Labour in Britains's Offshore Oil Industry. London: Mansell Publishing Limited.

WYNNE, B., 1988. Unruly technology: Practical rules, impractical discourses and public understanding. Social Studies of Science, 18:147-167. 